\title{
THE LEGAL BASIS OF LIABILITY FOR THE DAMAGE CAUSED DURING THE OPERATION OF AN AUTONOMOUS VEHICLE
}

\author{
Aleksey Yu. Churilov \\ Tomsk State University of Control Systems and Radioelectronics, Tomsk, Russian Federation
}

\begin{abstract}
Introduction: the advantages of implementing the driving technologies are obvious - the accessibility of vehicles for people who cannot drive because of their physical or mental deficiencies; the environmental performance of such vehicles; the reduction in accidents caused by mistakes of drivers. At the same time, the legal regulation of the relations connected with the operation of autonomous cars leaves much to be desired. Methods: the methodological framework for the study is a set of methods of scientific knowledge, among which the main are the methods of historicism, system, analysis, as well as the comparative law method. Results: the author researched the main theories potentially applicable in considering the liability for the damage caused by the operation of an autonomous vehicle. Conclusions: it is established that the current level of the legislative regulation of the compensation for the damage caused by the operation of an autonomous car is not sufficient; the most promising solution to the problem is proposed.
\end{abstract}

Key words: responsibility, damage, autonomous car, source of increased danger, legal regulation.

Citation. Churilov A.Yu. The Legal Basis of Liability for the Damage Caused During the Operation of an Autonomous Vehicle. Legal Concept, 2018, vol. 17, no. 4, pp. 30-34. DOI: https://doi.org/10.15688/lc.jvolsu.2018.4.4

\section{ПРАВОВЫЕ ОСНОВЫ ОТВЕТСТВЕННОСТИ ЗА ВРЕД, ПРИЧИНЕННЫЙ ПРИ ЭКСПЛУАТАЦИИ АВТОНОМНОГО АВТОМОБИЛЯ}

\author{
Алексей Юрьевич Чурилов \\ Томский государственный университет систем управления и радиоэлектроники, \\ г. Томск, Российская Федерация
}

\begin{abstract}
Введение: преимущества внедрения технологий вождения очевидны - доступность автомобилей для людей, которые не могут управлять автомобилем в силу физических или психологических недостатков; экологическая эффективность таких автомобилей; снижение количества аварий, вызванных ошибками водителей. Вместе с тем правовое регулирование отношений, связанных с эксплуатацией автономных автомобилей, оставляет желать лучшего. Методы: методологическую основу исследования составляет совокупность методов научного познания, среди которых основное место занимают методы историзма, системности, анализа, а также сравнительно-правовой метод. Результаты: проведено исследование основных теорий, потенциально применимых при рассмотрении вопросов ответственности за вред, причиненный при эксплуатации автономного автомобиля. Выводы: установлено, что текущий уровень законодательного регулирования возмещения ответственности за вред, причиненный при эксплуатации автономного автомобиля, недостаточен, предложен наиболее перспективный вариант решения проблемы.

Ключевые слова: ответственность, вред, автономный автомобиль, источник повышенной опасности, правовое регулирование.
\end{abstract} $\underset{0}{\infty}$ ватату

Цитирование. Чурилов А. Ю. Правовые основы ответственности за вред, причиненный при эксплуатации автономного автомобиля // Legal Concept = Правовая парадигма. - 2018. - Т. 17, № 4. - C. 30-34. DOI: https: //doi.org/10.15688/lc.jvolsu.2018.4.4 


\section{Введение}

Автономным, или беспилотным (в зависимости от степени автоматизации), автомобилем считается такой автомобиль, у которого как минимум один из критических аспектов управления (торможение, управление на дороге, ускорение) контролируется компьютером без непосредственного участия водителя [7]. Многие страны предпринимают попытки урегулировать отношения по поводу самоуправляемых автомобилей [14]. Отечественные исследователи также вносят свои предложения по совершенствованию законодательства в этой сфере [1]. Несмотря на это, развитие технологий все же опережает развитие права. Так, до сих пор остается неразрешенным вопрос об ответственности за вред, причиненный при эксплуатации автономного автомобиля.

В зарубежной доктрине и практике сложилось множество теорий, основные положения которых по аналогии можно применить при рассмотрении ответственности за вред, причиненный при эксплуатации беспилотного автомобиля, в частности, теории, раскрывающие особенности ответственности за вред, причиненный при эксплуатации лифта [9; 11]; вред, причиненный автопилотом корабля, самолета или поезда [9; 17]; вред, причиненный водителем-человеком [17].

\section{Анализ основных теорий}

Ответственность за беспилотные автомобили действительно можно сравнить с ответственность при эксплуатации лифта. Пассажир лифта лишь нажимает кнопку, и лифт доставляет его на нужный этаж. При этом очевидно, что эксплуатация лифтов сопряжена с высоким уровнем опасности для жизни, здоровья и имущества людей, большими размерами причиняемого ущерба при наступлении возможных аварий [2; 9]. Ответственность за вред, причиненный личности или имуществу, по общему правилу, возмещается не лицом, которое нажало кнопку вызова лифта или выбора этажа, а владельцем лифта [15; 16]. Вместе с тем, в отличие от поездки на лифте, где человек совершенно не имеет контроля над ним, при поездке на беспилотном автомобиле в настоящее время водитель все же сохраняет определен- ную возможность контроля. Более того, он может ненадлежаще использовать алгоритмы управления беспилотного автомобиля: указать превысить скорость, игнорировать предупреждения автомобиля, использовать беспилотный автомобиль на дорогах, которые не предназначены для этого. На человека в автономном автомобиле, в отличие от пассажира лифта, возлагаются обязанности по контролю за ситуацией на дороге, несмотря на отсутствие прямого управления автомобилем [8]. Следовательно, в настоящее время невозможно применить аналогию ответственности за вред, причиненный при эксплуатации лифта, к беспилотным автомобилям.

Другая теория состоит в том, что суды могут применять при разрешении споров о возмещении вреда, причиненного при эксплуатации автономного автомобиля, по аналогии нормы, регулирующие ответственность за вред, причиненный автопилотами кораблей, самолетов [9] или поездов [11]. Действительно, в отличие от лифта, автопилот подразумевает необходимость ограниченного управления со стороны человека [10]. Ответственность за причиненный вред в таком случае несет производитель системы автопилота, если не докажет вину управлявшего лица (что и происходит в большинстве случаев) [9].Такая система распределения ответственности, скорее всего, увеличит ответственность владельца беспилотного автомобиля, что может снизить спрос на них. Однако производитель автопилота может быть привлечен к ответственности в случае, если вред был причинен в результате предвидимого ненадлежащего использования автопилота [13], что может освободить, к примеру, водителей-новичков от ответственности.

К ответственности за вред, причиненный при эксплуатации автономного автомобиля, в рамках отечественного правопорядка потенциально применимы нормы об ответственности за вред, причиненный деятельностью, создающей повышенную опасность для окружающих. Автомобиль в процессе его эксплуатации традиционно признается источником повышенной опасности [3; 5]. Эта концепция хороша тем, что поглощает собой теорию как водителя-человека, так и автопилота, поскольку, по общему правилу, автопилотируемые транспортные 
средства являются источниками повышенной опасности по смыслу, придаваемому этому явлению сложившейся судебной практикой и доктриной. Вместе с тем такой подход необоснованно повышает ответственность владельца беспилотного автомобиля, поскольку он, как правило, не участвует в его управлении, либо его участие существенно ограничено. Представляется, что «деятельность» по эксплуатации беспилотного автомобиля сродни скорее деятельности пассажира, нежели водителя, в связи с чем применение такого механизма является нецелесообразным.

В источниках римского частного права некоторые авторы находят возможность рассматривать беспилотный автомобиль через призму искусственного интеллекта, который этим автомобилем управляет, как некоего представителя. По замечанию исследователей, искусственный интеллект похож на «цифрового раба», разумного не-субъекта права, который способен своими действиями создавать для владельца права и обязанности [6]. Действительно, еще в Древнем Риме раба называли instrumentum vocale, а когда того потребовали экономические интересы господина, было признано, что при помощи раба может быть расширен круг правовых отношений господина. За рабом была признана способность вступать в имущественные сделки ex persona domini, создавая при помощи этих сделок права для господина. Также было установлено, что если раб причинит кому-нибудь имущественный вред, украдет, испортит вещь, то господин обязан либо возместить этот вред, либо выдать раба потерпевшему [4]. Однако проблема определения лица, ответственного за вред, причиненный при эксплуатации беспилотного автомобиля, остается, поскольку однозначно решить, чьим представителем является искусственный интеллект автомобиля - производителя или владельца, затруднительно с точки зрения экономико-правовой целесообразности такого решения.

\section{Перспективный подход}

Некоторые исследователи, разумно оценивая риски возложения ответственности за вред, причиненный беспилотным автомобилем, как для производителей, так и для потребителей, предла- гают внедрить систему, схожую с системой страхования ответственности за вред, причиненный в результате эксплуатации атомных электростанций $[11]^{1}$. Суть его состоит в двухуровневом страховании ответственности. Первый уровень - это обычный договор страхования на сумму, устанавливаемую законодательством. В пределах этой суммы все выплаты за ущерб осуществляются компанией, застраховавшей риски. Для осуществления выплат свыше суммы первого уровня создается специальный фонд, в который владельцы атомных электростанций вносят определенные законом суммы.

Во многих странах, в том числе и в России, владельцы автомобилей обязаны страховать ответственность за вред, причиненный при его эксплуатации. Однако в случае превышения ущерба над страховой суммой нарушитель обязан произвести выплаты из собственных средств.

В случае создания фонда второго уровня эти выплаты будут осуществляться из средств этого фонда, что снизит риски материальных потерь для покупателей беспилотных автомобилей, а наличие обязательной страховки последних снижает имущественные риски и потенциальные расходы производителей беспилотных автомобилей.

\section{Вывод}

В качестве вывода следует отметить, что регулирование ответственности за вред, причиненный беспилотными автомобилями, оставляет желать много лучшего, особенно с учетом того, что многие теоретические концепции, нормы права, сложившаяся судебная практика неприменимы к отношениям, возникающим по поводу все более и более усложняющихся результатов деятельности человека.

\section{ПРИМЕЧАНИЕ}

1 Речь идет о Тhe Price-Anderson Nuclear Industries Indemnity Act.

\section{СПИСОК ЛИТЕРАТУРЫ}

1. Архипов, В. В. Искусственный интеллект и автономные устройства в контексте права: о 
разработке первого в России закона о робототехнике / В. В. Архипов, В. Б. Наумов // Труды СПИИРАН. - 2017. - № 6. - С. 46-62.

2. Бобровская, О. Н. Лифт (лифтовое оборудование) как объект страхования общего имущества многоквартирного дома: спорные вопросы владения и содержания / О.Н.Бобровская // Современное право. - 2015. - № 5. - С. 64-68.

3. Вайпан, В. А. Правовое регулирование транспортной деятельности / В. А. Вайпан // Право и экономика. - 2012. - № 6. - С. 18-42.

4. Римское частное право : учебник / В. А. Краснокутский, И. Б. Новицкий, И. С. Перетерский [и др.] ; под ред. И. Б. Новицкого, И. С. Перетерского. - М. : Юристь, 2004. - 544 с.

5. Рожкова, М. А. Об источнике повышенной опасности / М. А. Рожкова // Вестник ВАС РФ. 2002. - № 2. - C. 88-100.

6. Chopra, S. Artificial Agents and the Contracting Problem: A Solution Via an Agency Analysis / S. Chopra and L. White // University of Illinois Journal of Law Technology \& Policy. - 2009. № 2. - P. 363-403.

7. Colonna, K. Autonomous Cars and Tort Liability: Why the Market Will «Drive» Autonomous Cars Out of the Marketplace / K. Colonna // Journal of Law, Technology \& the Internet. - 2012. - Vol. 4, № 2. P. 81-130.

8. Endsley, M. R. From Here to Autonomy: Lessons Learned From Human-Automation Research / M. R. Endsley // Human Factors. - 2017. - Vol. 59, iss. 1. - P. 5-27. - DOI: 10.1177/0018720816681350.

9. Gurney, J. K. Sue My Car Not Me: Products Liability and Accidents Involving Autonomous Vehicles / J. K. Gurney // University of Illinois Journal of Law, Technology \& Policy. - 2013. № 2. - P. 247-277.

10. LeValley, D. Autonomous Vehicle LiabilityApplication of Common Carrier Liability/ D. LeValley // Seattle University Law Review. - 2013. - Vol. 36, iss. 5. - P. 5-26.

11. Margaret Fisher Knight v. Otis Elevator Company and Hartford Insurance Group and Atwell, Vogel\& Sterling, Inc. v. Western Electric Company, Third-Party, 596 F.2d 84, $3^{\text {rd }}$ Cir. (1979). - Electronic data. - Mode of access: https://ru.scribd.com/ document/320773951/Margaret-Fisher-Knight-v-OtisElevator-Company-and-Hartford-Insurance-Groupand-Atwell-Vogel-Sterling-Inc-v-Western-ElectricCompany-Third-Part. - Title from screen.

12. Matthews, Z. Defending the First Wave: Autonomous Trucking and the Death of Driver Negligence? / Zach Matthews \& Christopher K. Jones // DRI. - 2015. - P. 59-64.

13. National Highway Traffic SafetyAdministration. Odi resume. Investigation PE 16-007. - Electronic text data. - Mode of access: https://static.nhtsa.gov/odi/inv/ 2016/INCLA-PE16007-7876.PDF. - Title from screen.

14. Swanson, A. Somebody Grab the Wheel!: State Autonomous Vehicle Legislation and the Road to a National Regime / A. Swanson // Marquette Law Review. - 2014. - Vol. 97, iss. 4. - P. 1085-1147.

15. United States of America v. General Motors Corporation, a Corporation, Appellant, 518 F.2d 420 (D.C. Cir. 1975). - Electronic data. - Mode of access: https://aw.justia.com/cases/federal/appellate-courts/ F2/518/420/282090/. - Title from screen.

16. Webb, K. C. Products Liability and Autonomous Vehicles: Who's Driving Whom? / K. C. Webb // Richmond Journal of Law \& Technology. - 2016. Vol. XXIII, iss. 4.

17. Zohn, J. R. When Robots Attack: How Should the Law Handle Selfdriving Cars That Cause Damages / J. R. Zohn // Journal of Law, Technology \& Policy. 2015. - № 2. - P. 461-485.

\section{REFERENCES}

1. Arkhipov V.V., Naumov V.B. Iskusstvennyy intellekt $\mathrm{i}$ avtonomnye ustroystva $\mathrm{v}$ kontekste prava: o razrabotke pervogo v Rossii zakona o robototekhnike [Artificial Intelligence and Autonomous Devices in the Context of Law: the Development of the First Law on Robotics in Russia]. Trudy SPIIRAN, 2017, no. 6, pp. 46-62.

2. Bobrovskaya O.N. Lift (liftovoe oborudovanie) kak obyekt strakhovaniya obshchego imushchestva mnogokvartirnogo doma: spornye voprosy vladeniya i soderzhaniya [Elevator (Elevator Equipment) as Insurable Interest in Common Property in an Apartment Building Insuranse: Controversial Issues of Ownership and Maintenance]. Sovremennoe pravo, 2015, no. 5, pp. 64-68.

3. Vaypan V.A. Pravovoe regulirovanie transportnoy deyatelnosti [Legal Regulation of Transport Services]. Pravo i ekonomika, 2012, no. 6, pp. 18-42.

4. Krasnokutskiy V.A., Novitskiy I.B., Pereterskiy I.S., et al. Rimskoe chastnoe pravo [Roman Civil Law]. Moscow, Yurist Publ., 2004. 544 p.

5. Rozhkova M.A. Ob istochnike povyshennoy opasnosti [On the Source of Increased Danger]. Vestnik $V A S R F$ [Herald of the Supreme Arbitration Court of the Russian Federation], 2002, no. 2, pp. 88-100.

6. Chopra S., White L. Artificial Agents and the Contracting Problem: A Solution Via an Agency Analysis. Journal of Law Technology \& Policy, 2009, no. 2, pp. 363-403.

7. Colonna K. Autonomous Cars and Tort Liability: Why the Market Will "Drive" Autonomous Cars out of the Marketplace. Journal of Law, Technology \& the Internet, 2012, vol. 4, no. 2, pp. 81-130. 
8. Endsley M.R. From Here to Autonomy: Lessons Learned From Human-Automation Research. Human Factors, 2017, vol. 59, iss. 1, pp. 5-27. DOI: $10.1177 / 0018720816681350$.

9. Gurney J.K. Sue My Car Not Me: Products Liability and Accidents Involving Autonomous Vehicles. Journal of Law, Technology \& Policy, 2013, no. 2, pp. 247-277.

10. LeValley D. Autonomous Vehicle Liability Application of Common Carrier Liability. Seattle University Law Review, 2013, vol. 36, iss. 5, pp. 5-26.

11. Margaret Fisher Knight v. Otis Elevator Company and Hartford Insurance Group and Atwell, Vogel \& Sterling, Inc. v. Western Electric Company, Third-Party, 596 F.2d, 84, $3^{\text {rd }}$ Cir. (1979). URL: https://ru.scribd.com/document/320773951/ Margaret-Fisher-Knight-v-Otis-ElevatorCompany-and-Hartford-Insurance-Group-andAtwell-Vogel-Sterling-Inc-v-Western-ElectricCompany-Third-Part.
12. Matthews Z., Jones Ch.K. Defending the First Wave: Autonomous Trucking and the Death of Driver Negligence? DRI, 2015, pp. 59-64.

13. National Highway Traffic Safety Administration. Odi Resume. Investigation PE 16-007. URL: https:// static.nhtsa.gov/odi/inv/2016/INCLA-PE16007-7876.PDF.

14. Swanson A. Somebody Grab the Wheel!: State Autonomous Vehicle Legislation and the Road to a National Regime. Marquette Law Review, 2014, vol. 97, iss. 4, pp. 1085-1147.

15. United States of America v. General Motors Corporation, a Corporation, Appellant, 518 F.2d 420 (D.C. Cir. 1975). URL: https://law.justia.com/cases/ federal/appellate-courts/F2/518/420/282090/.

16. Webb K.C. Products Liability and Autonomous Vehicles: Who's Driving Whom? Richmond Journal of Law \& Technology, 2016, vol. XXIII, iss. 4.

17. Zohn J.R. When Robots Attack: How Should the Law Handle Selfdriving Cars That Cause Damages. Journal of Law, Technology \& Policy, 2015, no. 2, pp. 461-485.

\section{Information about the Author}

Aleksey Yu. Churilov, Senior Lecturer, Department of Civil Law, Tomsk State University of Control Systems and Radioelectronics, Prosp. Lenina, 40, 634050 Tomsk, Russian Federation, Lefikantor@yandex.ru, https://orcid.org/0000-0001-9435-1626

\section{Информация об авторе}

Алексей Юрьевич Чурилов, старший преподаватель кафедры гражданского права, Томский государственный университет систем управления и радиоэлектроники, просп. Ленина, 40, 634050 г. Томск, Российская Федерация, Lefikantor@yandex.ru, https://orcid.org/0000-0001-9435-1626 